\title{
SHORT-TERM EFFECT OF MONOCUSPID VALVES ON PULMONARY INSUFFICIENCY AND CLINICAL OUTCOME AFTER SURGICAL REPAIR OF TETRALOGY OF FALLOT
}

Jean-Luc Bigras, MD

Christine Boutin, MD

Brian W. McCrindle, MD, MPH

Ivan M. Rebeyka, MD
In the surgical repair of tetralogy of Fallot, monocuspid valves are sometimes inserted within a transannular patch to prevent pulmonary insufficiency. To determine whether this monocuspid valve prevents shortterm postoperative pulmonary insufficiency and improves clinical outcome, we reviewed clinical data and preoperative and postoperative echocardiographic variables from 61 patients who underwent one of three different procedures for repair of tetralogy of Fallot between August 1992 and March 1994. We compared features from 24 patients who had undergone transannular patch repair with a monocuspid valve (patch-valve) with those from 17 patients who had undergone patch repair without a monocuspid valve (patch) and 20 patients who had undergone repair without a transannular patch (no patch). We used the ratio of pulmonary valve insufficiency jet width to pulmonary artery diameter, as measured by color-flow Doppler flowmetry, as an index of severity of pulmonary insufficiency. Moderate to severe pulmonary insufficiency was arbitrarily defined as a ratio of at least 0.50. We found no significant differences in ratios among the patch-valve group $(0.73 \pm 0.25$, mean \pm standard deviation $)$, the patch group $(0.79 \pm$ $0.20)$, and the no patch group $(0.59 \pm 0.23)$. The percentages of patients with moderate to severe pulmonary insufficiency did not differ among the three groups (patch-valve $80 \%$, patch $90 \%$, no patch $64 \%$ ). Clinical data (including mortality, number of reoperations, intensive care unit and hospital lengths of stay, and postoperative hemodynamics) were similar in the three groups. We conclude that insertion of a monocuspid valve in repair of tetralogy of Fallot does not prevent short-term postoperative pulmonary insufficiency and does not improve immediate postoperative outcome for these patients. (J Thorac Cardiovasc Surg 1996;112:33-7)
A fter the surgical repair of tetralogy of Fallot with a transannular patch, infants have pulmonary insufficiency. ${ }^{1}$ This pulmonary insufficiency may be detrimental in either the short term or the long term. ${ }^{2-6}$ The short-term postoperative period is characterized by a sudden hemodynamic change from a pressure-loaded right ventricle to a volumeloaded ventricle; the addition of pulmonary insufficiency further increases the volume load on the right

From The Hospital for Sick Children, University of Toronto, Toronto, Ontario, Canada.

Received for publication Oct. 9, 1995; revisions requested Dec. 4, 1995; revisions received Jan. 4, 1995; accepted for publication Jan. 9, 1995.

Address for reprints: Christine Boutin, MD, Division of Cardiology, The Hospital for Sick Children, 555 University Ave., Toronto, Ontario, Canada M5G 1 X8.

Copyright (C) 1996 by Mosby-Year Book, Inc.

$0022-5223 / 96 \$ 5.00+0 \quad \mathbf{1 2 / 1 / 7 1 7 2 4}$ ventricle. The long-term postoperative period is characterized by chronic volume overload of the right ventricle. As a result, the ventricle may dilate and may be unable to maintain normal pulmonary circulation. ${ }^{7}$ The insertion of a monocuspid valve within the transannular patch to prevent pulmonary insufficiency has been supported by various investigators. ${ }^{8-12}$ Such a procedure has been shown, however, to fail to prevent pulmonary insufficiency in the long term. ${ }^{12-16}$ Whether the insertion of a monocuspid valve improves short-term postoperative pulmonary insufficiency ${ }^{12,17}$ or outcome is as yet unclear. The purposes of this retrospective study were to determine by echocardiography whether the insertion of a monocuspid valve within a transannular patch improves short-term pulmonary insufficiency after repair of tetralogy of Fallot and to determine from clinical data whether patients undergoing transannular patch repair who receive a monocuspid 
valve have a better early postoperative clinical outcome than those who do not.

\section{Materials and methods}

We reviewed the echocardiographic data and charts of all patients who had complete repair of tetralogy of Fallot at The Hospital for Sick Children, Toronto, Canada, between August 1992 and March 1994. We excluded patients who underwent insertion of a conduit or a bioprosthetic valve. Sixty-one patients were included in the study.

In our institution, a transannular patch is inserted when the pulmonary valve orifice or right ventricular outflow tract is more than $2 \mathrm{SD}$ smaller than normal after intraoperative pulmonary valvotomy. There is no institutional policy other than surgeon preference concerning the insertion of a monocuspid valve. We divided the population study into three groups according to type of repair: patients who underwent transannular patch repair with insertion of a monocuspid valve (patch-valve, $n=$ 24), patients who underwent transannular patch without insertion of a valve (patch, $n=17$ ), and patients who underwent pulmonary valvotomy without a transannular patch (no patch, $n=20$ ).

Patients in the no patch group served as a reference group. In the patch-valve group, three types of monocuspid valve were used. Seven patients had a monocuspid valve constructed from a portion of autologous pericardium, 11 patients had a commercial monocuspid valved patch (Polystan, Copenhagen, Denmark), and six patients had a patch excised from a homograft aortic valve conduit containing one aortic valve cusp in continuity with the anterior mitral leaflet. The widths of the Polystan and homograft monocuspid valve patches were selected to achieve a normal pulmonary anulus diameter for body surface area. The autologous pericardial monocuspid valve was constructed by securing a portion of pericardium $30 \%$ larger than the width of the outflow tract patch.

We reviewed patients' preoperative echocardiograms and their charts at the time of the operation. From the preoperative echocardiograms, we collected variables reflective of the severity of the tetralogy of Fallot, including dimensions of the left, right, and main pulmonary artery and the right ventricular outflow tract gradient as measured by continuous-wave Doppler flowmetry. To evaluate for patient selection bias regarding repair type, we compared patients' ages, weights, and hemoglobin levels, and noted whether previous systemic-pulmonary (modified Blalock-Taussig) shunt had been required. We also compared the frequency of insertion of a monocuspid valve among the four surgeons.

Postoperative echocardiography was used to determine whether the monocuspid valve prevented short-term postoperative pulmonary insufficiency. Specifically, we evaluated the valve's competency and relief of the pulmonary outflow tract obstruction by assessing three variables: pulmonary valve insufficiency jet width, as measured by color Doppler flowmetry; pulmonary valve diameter in early diastole; and right ventricular outflow tract gradient, as measured by continuous-wave Doppler flowmetry. From these variables, we calculated the ratio of pulmo- nary insufficiency to pulmonary artery diameter, which is an index of the severity of pulmonary insufficiency. We arbitrarily decided that a ratio of at least 0.50 would represent moderate to severe pulmonary insufficiency.

To determine whether patients with a transannular patch and a monocuspid valve had a better clinical outcome after operation than did patients without a monocuspid valve, we collected data from the operation and from the hospitalization. The data related to the operation included cardiopulmonary bypass time, aortic crossclamp time, postoperative right ventricle-aorta pressure ratio, and the type of monocuspid valve inserted. The data related to the postoperative course included length of stay in the intensive care unit, length of hospitalization, death during hospitalization, and need for reoperation. We considered all patients who required reopening or closure of the chest once in the intensive care unit to have undergone reoperation. In addition, we assessed hemodynamic variables recorded in the intensive care unit at 6 , 12,24 , and 48 hours after operation. These included need for oxygen (inspired fraction of oxygen), acid-base status ( $\mathrm{pH}$ and base excess), partial pressures of oxygen and carbon dioxide, mean blood pressure, central venous pressure, urine output, and need for inotropic support.

The statistical analyses of continuously distributed data were performed with one-way analysis of variance followed by a Bonferroni adjustment test to determine significant differences between groups. Nonparametric data were analyzed by $\chi^{2}$ and Kruskal-Wallis analysis of variance. Analysis of variance with repeated measurements was performed for data sampled at different time intervals. A $p$ value less than 0.05 was considered significant. Data are expressed as means ( \pm standard deviation) and medians (with ranges).

\section{Results}

The preoperative echocardiograms and the patients' characteristics were similar at operation (Table I). Postoperative pulmonary insufficiency, as indicated by the ratio of pulmonary valve insufficiency jet width over pulmonary artery diameter, was similar in the two groups that underwent transannular patch repair without or with a monocuspid valve (Table II). This ratio was also similar among the different types of monocuspid valves $(0.68 \pm 0.31$ for autologous pericardium $[n=7]$, $0.77 \pm 0.28$ for Polystan valves $[n=11]$, and $0.70 \pm$ 0.10 for homograft valves $[n=6]$ ).

Clinical outcomes were similar between the two groups that underwent transannular patch repair with or without a monocuspid valve (Table III). One patient in the patch-valve group had a prolonged postoperative course and remained in the intensive care unit for 67 days. The patch-valve group had a longer cardiopulmonary bypass time than did the no patch group (Table III). Clinical outcomes were similar for the no patch group, except that fewer 
Table I. Preoperative characteristics

\begin{tabular}{lccc}
\hline & $\begin{array}{c}\text { Patch-valve } \\
(n=24)\end{array}$ & $\begin{array}{c}\text { Patch } \\
(n=20)\end{array}$ & $\begin{array}{c}\text { No patch } \\
(n=17)\end{array}$ \\
\hline Preoperative echocardiography & & & $17(5-50)$ \\
Age (mo) & $23(0-5)$ & $73(41-119)$ & $16(8-62)$ \\
RVOT gradient (mm Hg) & $67(44-90)$ & $1.0 \pm 0.3$ & $69(39-91)$ \\
PA diameter (cm) & $0.8 \pm 0.2$ & $0.7 \pm 0.2$ & $0.9 \pm 0.1$ \\
LPA proximal diameter (cm) & $0.7 \pm 0.2$ & $0.7 \pm 0.1$ & $0.8 \pm 0.2$ \\
RPA proximal diameter (cm) & $0.7 \pm 0.2$ & $0.8 \pm 0.2$ & $0.7 \pm 0.1$ \\
RPA distal diameter (cm) & $0.8 \pm 0.2$ & & $0.8 \pm 0.2$ \\
Patient characteristics & & 4 & 8 \\
Previous shunts (no. patients) & 12 & $18(7-52)$ & $17(11-63)$ \\
Age at operation (mo) & $26(10-98)$ & $10(6-17)$ & $10(4-20)$ \\
Weight at operation (kg) & $10(7-20)$ & $147 \pm 20$ & $154 \pm 26$ \\
Hemoglobin at operation (gm/L) & $152 \pm 15$ & \\
\hline
\end{tabular}

Data are means \pm standard deviation, except for age, RVOT, age at operation, and weight at operation, which are expressed as median with range in parentheses. $R V O T$, Right ventricular outflow tract; $P A$, pulmonary artery; $L P A$, left pulmonary artery; $R P A$, right pulmonary artery.

Table II. Postoperative echocardiographic variables

\begin{tabular}{lccc}
\hline & $\begin{array}{c}\text { Patch-valve } \\
(n=24)\end{array}$ & $\begin{array}{c}\text { Patch } \\
(n=20)\end{array}$ & $\begin{array}{c}\text { No patch } \\
(n=17)\end{array}$ \\
\hline Age (mo) & $23(10-98)$ & $18(7-52)$ & $17(11-64)$ \\
Time after operation (days) & $7(0-61)$ & $3(0-41)$ & $4(0-43)$ \\
RVOT gradient (mm Hg) & $8(1-51)^{*}$ & $7(1-17)^{*}$ & $27(6-51)$ \\
PA diameter (cm) & $1.5 \pm 0.2^{*}$ & $1.4 \pm 0.3$ & $1.2 \pm 0.3$ \\
PI jet width (cm) & $1.0 \pm 0.4^{*}$ & $1.0 \pm 0.2^{*}$ & $0.6 \pm 0.2$ \\
PI/PA ratio & $0.73 \pm 0.25$ & $0.79 \pm 0.20$ & $0.59 \pm 0.23$ \\
PI/PA ratio $\geq 0.50$ (\% of patients) & 80 & 90 & 64
\end{tabular}

Data are means \pm standard deviation except for age, time after operation, and RVOT, which are expressed as median with range in parentheses. RVOT, Right ventricular outflow tract; $P A$, pulmonary artery; $P I$, pulmonary insufficiency.

${ }^{*} p<0.05$ vs no patch group.

patients were receiving inotropic drugs at 48 hours after operation than in the two other groups (Table III).

Among the four surgeons, surgeon 3 inserted a monocuspid valve less frequently than did the other three (surgeon $1,75 \%$ of patients; surgeon $2,78 \%$; surgeon $3,21 \%$; surgeon $4,80 \%$; $p<0.01$ ).

\section{Discussion}

This study shows that the insertion of these different types of monocuspid valves does not prevent short-term pulmonary insufficiency after repair of tetralogy of Fallot. The reason for persistence of pulmonary insufficiency even when a monocuspid valve is inserted is unclear. The persistent pulmonary insufficiency we observed could be explained by such factors as the long distance to be covered by the monocuspid leaflet during rapid closure or irregular movements of the valve during closure as a result of leaflet buckling. ${ }^{18}$ Another cause could be that some monocuspid valves were tailored too wide. ${ }^{17}$ In addition, in contrast to other reports, ${ }^{11,19}$ we found that the different types of valve used did not affect pulmonary insufficiency, although this conclusion is limited by the small number of patients ( 7 autologous pericardium valves, 11 Polystan valves, and 6 homograft valves).

We found that $80 \%$ of patients who underwent transannular repair with insertion of a monocuspid valve had moderate to severe pulmonary insufficiency, which contrasts with the prevalence of $16 \%$ reported by Gundry and coworkers. ${ }^{12}$ This discrepancy could be explained by the different methods used to detect pulmonary insufficiency. Our classification of pulmonary insufficiency was based strictly on echocardiography, whereas their classification relied on either clinical examination, catheterization, or echocardiography, according to availability, which may have been less sensitive. Differences in surgical technique could also explain the discrepancy.

Our study also shows that patients who undergo transannular patch repair with the insertion of a monocuspid valve do not have a better clinical 
Table III. Surgical and postoperative variables

\begin{tabular}{|c|c|c|c|}
\hline & $\begin{array}{c}\text { Patch-valve } \\
(n=24)\end{array}$ & $\begin{array}{c}\text { Patch } \\
(n=20)\end{array}$ & $\begin{array}{l}\text { No patch } \\
(n=17)\end{array}$ \\
\hline Bypass time (min) & $149 \pm 34^{*}$ & $129 \pm 55$ & $107 \pm 22$ \\
\hline Aortic crossclamp time (min) & $47 \pm 15$ & $55 \pm 21$ & $47 \pm 11$ \\
\hline RV/AO pressure ratio after operation (\%) & $47 \pm 11$ & $50 \pm 13$ & $51 \pm 15$ \\
\hline Stay in intensive care (days) & $6(3-67)$ & $3(0-19)$ & $4(2-17)$ \\
\hline Stay in hospital (days) & $15(8-65)$ & $13(7-30)$ & $11(6-26)$ \\
\hline Number of deaths & 1 & 2 & 2 \\
\hline Reoperations (no. of patients) & 7 & 6 & 5 \\
\hline \multicolumn{4}{|l|}{ Postoperative variables at 48 hours } \\
\hline $\mathrm{FIO}_{2}$ & $0.47 \pm 0.17$ & $0.40 \pm 0.10$ & $0.48 \pm 0.13$ \\
\hline $\mathrm{pH}$ & $7.46 \pm 0.06$ & $7.46 \pm 0.03$ & $7.41 \pm 0.04$ \\
\hline Base excess $(\mathrm{mmol} / \mathrm{L})$ & $0.2 \pm 2.9$ & $-0.1 \pm 2.2$ & $-1.1 \pm 2.3$ \\
\hline $\mathrm{PO}_{2}(\mathrm{~mm} \mathrm{Hg})$ & $112 \pm 37$ & $122 \pm 42$ & $122 \pm 35$ \\
\hline $\mathrm{PCO}_{2}(\mathrm{~mm} \mathrm{Hg})$ & $34 \pm 6$ & $34 \pm 4$ & $37 \pm 6$ \\
\hline Mean blood pressure (mm Hg) & $74 \pm 7$ & $70 \pm 10$ & $72 \pm 8$ \\
\hline Central venous pressure (mm $\mathrm{Hg}$ ) & $12 \pm 4$ & $14 \pm 5$ & $14 \pm 4$ \\
\hline Urine output $\left(\mathrm{ml} \cdot \mathrm{kg}^{-1} \cdot \mathrm{hr}^{-1}\right)$ & $2.5 \pm 1.5$ & $2.2 \pm 1.4$ & $2.1 \pm 1.4$ \\
\hline Inotropic drug use (no. of patients) & $20 *$ & $12^{*}$ & 6 \\
\hline
\end{tabular}

Data are means \pm standard deviation, except for stay in intensive care unit and in hospital, which are expressed as median with range in parentheses. $R V$, Right ventricle; $\mathrm{AO}$, aorta; $\mathrm{FIO}_{2}$, inspired fraction of oxygen; $\mathrm{PO}_{2}$, oxygen tension; $\mathrm{PCO}_{2}$, carbon dioxide tension.

${ }^{*} p<0.05$ vs no patch group.

outcome after operation than do patients without a monocuspid valve. Neither did they have a worse outcome, except for the minor finding that cardiopulmonary bypass time was longer than in the reference group (no patch). The high reoperation rate was the result of inclusion of patients with delayed sternal closure within several days of the initial operation.

The clinical outcomes may have been affected by the lack of objective criteria or by selection bias. The criteria reported in the literature for insertion of a monocuspid valve are vague. Some authors recommend insertion of a monocuspid valve in cases of elevated pulmonary vascular resistance or in the presence of multiple pulmonary artery stenoses. ${ }^{19} \mathrm{In}$ our study, the preoperative echocardiographic results and patient characteristics at operation were similar among the three groups. Selection bias seems most related to the surgeon, as demonstrated by the different frequencies of monocuspid insertion among the surgeons. A randomized clinical trial may be warranted. The wide range of intervals for postoperative echocardiography also may have affected the degree of pulmonary insufficiency, although $91 \%$ of the patients had echocardiography performed within 14 days after operation.

In conclusion, insertion of these three types of monocuspid valve within a transannular patch for the surgical repair of tetralogy of Fallot does not prevent short-term postoperative pulmonary insufficiency. Furthermore, the immediate clinical outcome in patients that underwent transannular patch repair with the insertion of a monocuspid valve is not improved with respect to patients without a monocuspid valve. Although monocuspid valve insertion to prevent short-term postoperative pulmonary insufficiency may potentially improve early hemodynamic function, better surgical techniques for constructing and inserting a pulmonary monocuspid valve and better selection criteria are needed. ${ }^{18,20}$ We are currently evaluating an alternative method of pulmonary monocuspid valve construction and insertion.

We express our appreciation to Mimi Zeiger for the preparation of the manuscript.

\section{REFERENCES}

1. Kirklin JK, Kirklin JW, Blackstone EH, Milano AD, Pacifico A. Effect of transannular patching on outcome after repair of tetralogy of Fallot. Ann Thorac Surg 1989;48:783-91.

2. Austen WG, Greenfield LJ, Ebert PA, Morrow AG. Experimental study of right ventricular function after surgical procedures involving the right ventricle and pulmonic valve. Ann Surg 1962;155:606-13.

3. Ellison RG, Brown WJ, Yeh TJ, Hamilton WF. Surgical significance of acute and chronic pulmonary valvular insufficiency. J Thorac Cardiovasc Surg 1970;60:549-58.

4. Lange PE, Onnasch DG, Bernhard A, Heintzen PH. Left and right ventricular adaptation to right ventricular overload 
before and after surgical repair of tetralogy of Fallot. Am J Cardiol 1982;50:786-94.

5. Hügel W, Hannekum A, Schreiber S, Dalichau H. The hemodynamics and contractility of the right ventricle in the early postoperative phase following correction of tetralogy of Fallot. Thorac Cardiovasc Surg 1984;32:253-5.

6. Noera G, Gatti M, Massini C, Medici SI, Fattori G. Experimental right ventricular outflow tract reconstruction with a composite mitrathane monocusp patch: preliminary results. Thorac Cardiovasc Surg 1988;36:89-95.

7. Bove EL, Byrum CJ, Thomas FD, Kavey RW, Sondheimer $\mathrm{HM}$, Blackman MS, et al. The influence of pulmonary insufficiency on ventricular function following repair of tetralogy of Fallot: evaluation using radionuclide ventriculography. J Thorac Cardiovasc Surg 1983;85:691-6.

8. Marchand $P$. The use of a cusp-bearing homograft patch to the outflow tract and pulmonary artery in Fallot's tetralogy and pulmonary valve stenosis. Thorax 1967;22:497-509.

9. Trusler GA, Tyengar SR, Mustard WT. Reconstruction of the pulmonary valve and outflow tract. Circulation 1973;65:245-51.

10. Revuelta JM, Ubago JL, Duran CM. Composite pericardial monocusp patch for the reconstruction of right ventricular outflow tract. Thorac Cardiovasc Surg 1983;31:156-9.

11. Abdulali SA, Silverton NP, Yakirevich VS, Ionescu MI. Right ventricular outflow tract reconstruction with a bovine pericardial monocusp patch. J Thorac Cardiovase Surg 1985; 89:764-71.

12. Gundry SR, Razzouk AJ, Boskind JF, Bansal R, Bailey LL. Fate of the pericardial monocusp pulmonary valve for right ventricular outflow tract reconstruction. J Thorac Cardiovasc Surg 1994;107:908-13.
13. Ross D, Somerville J. Fascia-lata reconstruction of the right ventricular outflow tract. Lancet 1971;1:941-3.

14. Ionescu MI, Macartney FJ, Wooler GH, Gerbode F. Reconstruction of the right ventricle outlet with fascia lata composite graft. J Thorac Cardiovasc Surg 1972;63:60-74.

15. Trusler GA, Ishizawa E, Echevarre E. Use of autogenous pericardium and homograft aortic valves in pulmonary valve reconstruction: an experimental study. Can J Surg 1974;17: 16-9.

16. Egloff L, Turina M, Senning $\AA$. An experimental study on transannular patching of the right ventricular outflow tract with and without a pulmonary valve monocusp mechanism. Thorac Cardiovasc Surg 1981;29:246-51.

17. Sievers HH, Lange PE, Regensburger D, Yanka CA, Onnasch DG, Bürsch J, et al. Short-term hemodynamic results after right ventricular outflow tract reconstruction using a cusp-bearing transannular patch. J Thorac Cardiovasc Surg 1983:86:777-83.

18. Sievers HH, Storde U, Rohwedder EB, Lange PE, Onnasch DG, Heintzen PH, et al. Superior function of a bicuspid over a monocuspid patch for reconstruction of a hypoplastic pulmonary root in pigs. J Thorac Cardiovasc Surg 1993,105: 580-90.

19. Bogers AJ, Roofthooft M, Pisters H, Spitaels SE, Bos E. Long-term results of the gamma-irradiation-preserved homograft monocusp for transannular reconstruction of the right-ventricular outflow tract in tetralogy of Fallot. Thorac Cardiovasc Surg 1994;42:337-9.

20. Yamagishi M, Kurosawa H. Outflow reconstruction of tetralogy of Fallot using a Gore-Tex valve. Ann Thorac Surg 1993;56:1414-7. 